04,09

\title{
Люминесцентные свойства нелегированных кристаллов лангасита
}

\author{
(ㄱ Д.А. Спасский ${ }^{1}$, Н.С. Козлова ${ }^{2}$, А.П. Козлова ${ }^{2}$, Е.В. Забелина ${ }^{2,9}$, О.А. Бузанов ${ }^{3}$ \\ ${ }^{1}$ Научно-исследовательский институт ядерной физики им. Д.В. Скобельцына \\ Московского государственного университета им. М.В. Ломоносова, \\ Москва, Россия \\ ${ }^{2}$ Национальный исследовательский технологический университет „МИСиС“, \\ Москва, Россия \\ ${ }^{3}$ ОАО „Фомос-Материалс", \\ Москва, Россия \\ ฯ E-mail: zabelina.ev@misis.ru
}

(Поступила в Редакцию 15 октября 2018 г.)

Исследованы оптические и люминесцентные свойства кристаллов лантан-галлиевого силиката $\mathrm{La}_{3} \mathrm{Ga}_{5} \mathrm{SiO}_{14}$, выращенных в атмосфере аргона и аргона с добавлением кислорода. Представлены результаты расчетов структуры энергетических зон, проведенные с использованием модуля CASTEP в рамках обобщенного градиентного приближения и приближения локальной плотности. Определено значение ширины оптической запрещенной зоны кристалла $E_{g}^{\text {опт }}=5.1 \mathrm{eV}$. Показано, что при межзонном возбуждении для $\mathrm{La}_{3} \mathrm{Ga}_{5} \mathrm{SiO}_{14}$, выращенных в атмосфере аргона наблюдается полоса люминесценции с максимумом при $430 \mathrm{~nm}$, тогда как для кристалла, выращенного в атмосфере аргона с добавлением кислорода, в спектре люминесценции доминируют две полосы люминесценции с максимумами при 470 и $530 \mathrm{~nm}$. Природа центров свечения, отвечающих за данные полосы, обсуждается с привлечением данных расчетов электронной структуры. Показано влияние температуры на люминесцентные свойства $\mathrm{La}_{3} \mathrm{Ga}_{5} \mathrm{SiO}_{14}$. С использованием метода термостимулированной люминесценции показано наличие ловушек в $\mathrm{La}_{3} \mathrm{Ga}_{5} \mathrm{SiO}_{14}$, определена энергия активации ловушек.

Авторы благодарны за финансовую поддержку Министерству образования и науки Российской Федерации в рамках Государственного задания ВУЗу № 3.2794.2017/ПЧ, № 11.5583.2017/ИТР (11.5583.2017/7.8), № 11.6181.2017/ИТР (11.6181.2017/7.8). Исследования оптических свойств кристаллов проведены в межкафедральной учебно-испытательной лаборатории полупроводниковых материалов и диэлектриков „Монокристаллы и заготовки на их основе“ (ИЛМЗ) НИТУ „МИСиС“. Авторы благодарны проф. М.Г. Брику за проведение расчетов электронной структуры. Расчеты были проведены с использованием возможностей Вроцлавского вычислительного центра (http://wcss.pl), грант No. WCSS\#10117290.

DOI: 10.21883/FTT.2019.03.47233.283

\section{1. Введение}

Лантан - галлиевый силикат $\mathrm{La}_{3} \mathrm{Ga}_{5} \mathrm{SiO}_{14}$ (LGS, лангасит) является синтетическим кристаллом, разработанным в начале 80-х годов для применения в качестве лазерного материала [1-3]. Однако недостаточное оптическое качество не позволило использовать лангасит для этих целей. При этом лангасит обладает уникальной комбинацией температурных, акустических и оптических свойств, что делает этот материал перспективным для использования в разных областях $[1,3-5]$. В частности, большое значение пьезоэлектрического коэффициента и наличие термостабильных срезов позволили использовать кристаллы LGS для фильтров и резонаторов на поверхностных и объемных акустических волнах $[4,6,7]$.

К началу 2000-х оптическое качество кристалла было заметно улучшено $[8,9]$, что позволило вновь рассматривать лангасит в качестве оптического материала и стимулировало исследования его оптических и люминесцентных свойств. К настоящему времени кристаллы LGS рассматриваются в качестве матрицы для фосфо́ров, легированных редкоземельными и переходными элемен- тами [10-21], материала для генерации второй гармоники $[22,23]$, а также в качестве сцинтилляционного материала [24]. В частности, частичное разупорядочение кристаллической структуры LGS приводит к уширению линий поглощения редкоземельных элементов. Этот эффект позволяет увеличить эффективность переноса энергии излучения полупроводниковой подложки к люминофору в светодиодах. По этой причине люминесцентные свойства LGS, легированных различными ионами редкоземельных примесей, например, $\mathrm{Nd}^{3+}, \mathrm{Eu}^{3+}, \mathrm{Er}^{3+}$, $\mathrm{Ho}^{3+}, \mathrm{Dy}^{3+}$ широко исследовались в [10-18].

Кристаллы лангасита изоструктурны кальциевому галлиевому германату $\mathrm{Ca}_{3} \mathrm{Ga}_{2} \mathrm{Ge}_{4} \mathrm{O}_{14}$, пространственная группа симметрии $P 321$, тригональная симметрия [1]. Кристаллическая структура характеризуется наличием двух слоев, перпендикулярных кристаллографической оси с. Один из слоев состоит из ионов $\mathrm{La}^{3+}$, находящихся в окружении ионов кислорода, формирующих Томпсоновский куб, и ионов $\mathrm{Ga}^{3+}$, расположенных в кислородных октаэдрах. Другой слой содержит два различных типа кислородных тетраэдров: один тип тетраэдров заполнен ионами $\mathrm{Ga}^{3+}$ и $\mathrm{Si}^{4+}$ в соотношении $1: 1$, а другой только ионами $\mathrm{Ga}^{3+}[1]$. 
Литературные данные по люминесценции кристаллов LGS

\begin{tabular}{|c|c|c|c|}
\hline $\begin{array}{c}\text { Полоса } \\
\text { люминесценции, } \mathrm{nm}\end{array}$ & $\begin{array}{c}\text { Полоса } \\
\text { возбуждения, nm }\end{array}$ & $\begin{array}{c}\text { Предложенная модель } \\
\text { центра люминесценции }\end{array}$ & $\begin{array}{c}\text { Ссылка на источник, } \\
\text { дополнительная информация }\end{array}$ \\
\hline $\begin{array}{l}420 \\
500\end{array}$ & $\begin{array}{l}205 \\
245\end{array}$ & $\begin{array}{l}\text { Свечение АЛЭ* } \\
\text { Полоса, связанная } \\
\text { с дефектами структуры }\end{array}$ & $\begin{array}{c}{[27]} \\
T=5 \mathrm{~K}\end{array}$ \\
\hline $\begin{array}{l}320,380,485, \\
610 \\
310 \\
370 \\
480\end{array}$ & $\begin{array}{c}\alpha \text {-излучение } \\
205 \\
280 \\
260\end{array}$ & $\begin{array}{l}\text { Модель центров } \\
\text { не предложена } \\
\text { Свечение АЛЭ } \\
\text { Дефект неизвестной природы } \\
\mathrm{F}^{+} \text {-центры }\end{array}$ & $\begin{array}{c}{[24]} \\
T=300 \mathrm{~K}\end{array}$ \\
\hline $\begin{array}{l}370 \\
432\end{array}$ & $\begin{array}{l}260 \\
260\end{array}$ & $\begin{array}{l}\mathrm{Ga}-\mathrm{O} \text { тетраэдрические } \\
\mathrm{Ga}-\mathrm{O} \text { октаэдрические }\end{array}$ & $\begin{array}{c}{[28]} \\
T=300 \mathrm{~K}\end{array}$ \\
\hline 429 & 381 & $\mathrm{Ga}-\mathrm{O}$ октаэдрические & $\begin{array}{c}{[29]} \\
T=300 \mathrm{~K}\end{array}$ \\
\hline
\end{tabular}

Пр имечан и е. * АЛЭ — автолокализованный экситон.

Исследование природы дефектов является важной задачей для данного кристалла. Как правило, кристаллы лангасита выращиваются в атмосфере аргона или азота с добавлением нескольких процентов кислорода. Последнее необходимо для частичного подавления испарения легколетучего субоксида галлия из расплава $[9,25]$. В результате выращенные кристаллы имеют желтоватый оттенок, связанный с присутствием полосы поглощения в области 480-490 nm. Кроме этой полосы еще две или более полос поглощения регистрируются в УФ-области прозрачности кристалла. Отжиг кристаллов в вакууме приводит к обесцвечиванию кристалла, а выращивание в инертной атмосфере без добавления кислорода позволяет существенно ослабить полосы поглощения [26]. Однако в последнем случае невозможно вырастить высококачественные кристаллы больших объемов из-за нестехеометричности состава, возникающего вследствие испарения оксида галлия в процессе роста. Такие кристаллы содержат большое число объемных дефектов и включений.

Несмотря на интенсивные исследования оптических и электрических свойств кристаллов лангасита, природа дефектов, отвечающих за полосы поглощения в области прозрачности, к настоящему времени остается под вопросом [26]. В связи с этим следует расширить комплекс методов исследований, в частности, применить люминесцентный метод, который позволяет проводить исследования природы дефектов в кристаллах, и может быть использован и в случае лангасита. По данным, представленным в литературе, люминесцентные свойства нелегированных кристаллов исследованы слабо, при этом данные по положению полос свечения и их количеству противоречивы и не воспроизводятся из статьи в статью (см. таблицу) [24,27-29].

Целью настоящей работы является исследование оптических и люминесцентных свойств нелегированных кристаллов лангасита, выращенных в разных атмосфеpax, а также анализ этих свойств с учетом проведенных расчетов зонной структуры.

\section{2. Материалы и методики эксперимента}

Кристаллы LGS были выращены методом Чохральского в иридиевых тиглях в инертной атмосфере аргона (LGS (Ar)) и в атмосфере аргона с добавлением $2 \% \mathrm{O}_{2} \quad\left(\mathrm{LGS}\left(\mathrm{Ar}+2 \% \mathrm{O}_{2}\right)\right)$ в компании $\mathrm{OAO}$ „Фомос-Материалс“.

Спектры пропускания были измерены с использованием спектрофотометра „Cary-5000“ (Agilent Technologies) в диапазоне длин волн 200-2000 nm.

Люминесцентные свойства кристаллов исследовались при возбуждении излучением УФ/ВУФ спектрального диапазона, в том числе с использованием синхротронного излучения. Спектры люминесценции при возбуждении монохроматическим синхротронным излучением энергии $8 \mathrm{eV}$ при $T=15 \mathrm{~K}$ были измерены на установке в канале FINEST синхротронного излучения накопителя MAX-III (Лунд, Швеция) [30].

Спектры фотолюминесценции и возбуждения люминесценции были получены с использованием лабораторной установки Института физики университета Тарту (Эстония). Источником излучения служила дейтеривая лампа D 200 VUV (Ms Scientific). Излучение монохроматизировалось с использованием первичного вакуумного монохроматора McPherson Model 234/302. Образец помещался в оптический вакуумный криостат производства ARS, который позволяет проводить измерения в температурном диапазоне 6-350 K. Люминесценция регистрировалась с использованием вторичного монохроматора Shamrock 303i (Andor Technology) и головки счета фотонов Нamamatsu H8259. 
Кривые термостимулированной люминесценции (ТСЛ) измерялись после облучения кристалла электронным пучком в течение $15 \mathrm{~min}$. Измерения проводились в диапазоне $5-300 \mathrm{~K}$ при скорости нагрева $10 \mathrm{~K} / \mathrm{min}$. Линейность нагрева обеспечивалась температурным контролером LakeShore 331. Люминесценция регистрировалась с использованием монохроматора ARC SpectraPro-2300i, оснащенного головкой счета фотонов Hamamatsu H6240.

\section{3. Результаты и обсуждение}

\section{1. Расчет структуры энергетических зон $\mathrm{La}_{3} \mathrm{Ga}_{5} \mathrm{SiO} 14$}

Расчеты зонной структуры LGS были проведены из первых принципов с использованием модуля CASTEP пакета Materials Studio [31] в рамках обобщенного градиентного приближения GGA (Generalized Gradient Approach) [32] и приближения локальной плотности LDA (Local Density Approximation) [33,34]. Максимальная энергия плоских волн в базисе была выбрана $340 \mathrm{eV}$. Электронные конфигурации, использованные для расчета, были $5 s^{2} 5 p^{6} 5 d^{1} 6 s^{2}$ для La, $5 d^{3} 6 s^{2}$ для Ta, $3 d^{10} 4 s^{2} 4 p^{1}$ для $\mathrm{Ga}$ и $2 s^{2} 2 p^{4}$ для О. Расчеты проводились для свехрешетки с размерами $1 \times 1 \times 2$.

При расчетах зонной структуры LGS были получены оптимизированные постоянные решетки. В случае приближения GGA $a=b=8.4238 \AA, c=5.229 \AA$, тогда как в случае LDA $a=b=8.052 \AA, c=5.1248 \AA$ А. Угол $\gamma=120^{\circ}$ в обоих случаях. Таким образом, результаты расчета в приближении LDA ближе к данным экспериментальных измерений $(a=b=8.162 \AA, c=5.087 \AA$, угол $\gamma=120^{\circ}$ ) [1].

Результаты расчета зонной структуры LGS представлены на рис. 1 и 2. Запрещенная зона определяется прямыми электронными переходами в Г-точке, то есть в центре зоны Бриллюэна (рис. 1). Расчетное значение $E_{g}$ составило $3.003 \mathrm{eV}$ в GGA приближении. Ширина валентной зоны (В3) составляет около $8 \mathrm{eV}$. В3 сформирована, главным образом $2 p$ состояниями кислорода, которые гибридизируются с состояниями $3 p \mathrm{Si}$ и $5 d \mathrm{La}$ (рис. 2). Вклад электронных состояний $3 s \mathrm{Ga}$, которые также гибридизируются с $2 p$ состояниями кислорода, заметен, в основном, в нижней части В3. Ниже В3 расположены электронные состояния $3 d \mathrm{Ga}, 5 p \mathrm{La}$ и $2 s$ O, которые формируют верхние остовные уровни. Дно зоны проводимости (ЗП) формируется, главным образом, электронными состояниями $4 s \mathrm{Ga}$, тогда как при более высоких энергиях доминируют состояния $5 d \mathrm{La}$. Отметим, что результаты проведенного расчета несколько отличаются от представленных в работе [35], где за формирование дна ЗП отвечают состояния $5 d \mathrm{La}$. Отличие может быть связано с различными методами, использованными для расчета зонной структуры.

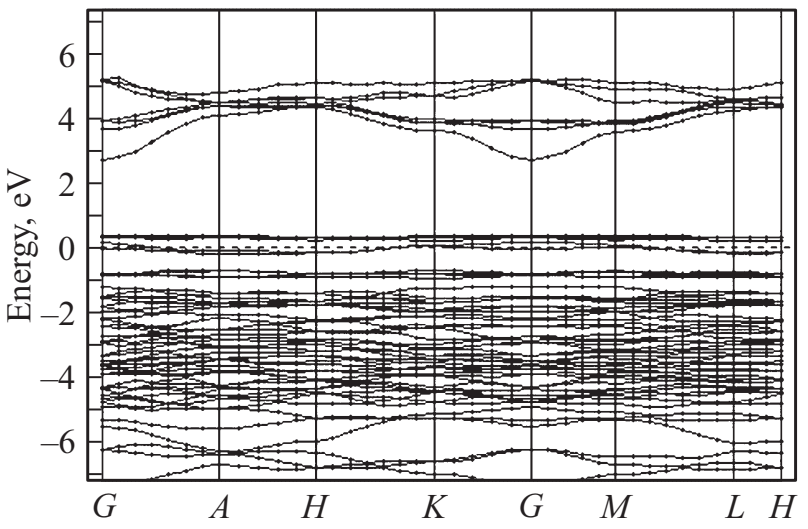

Рис. 1. Структура энергетических зон кристалла LGS.

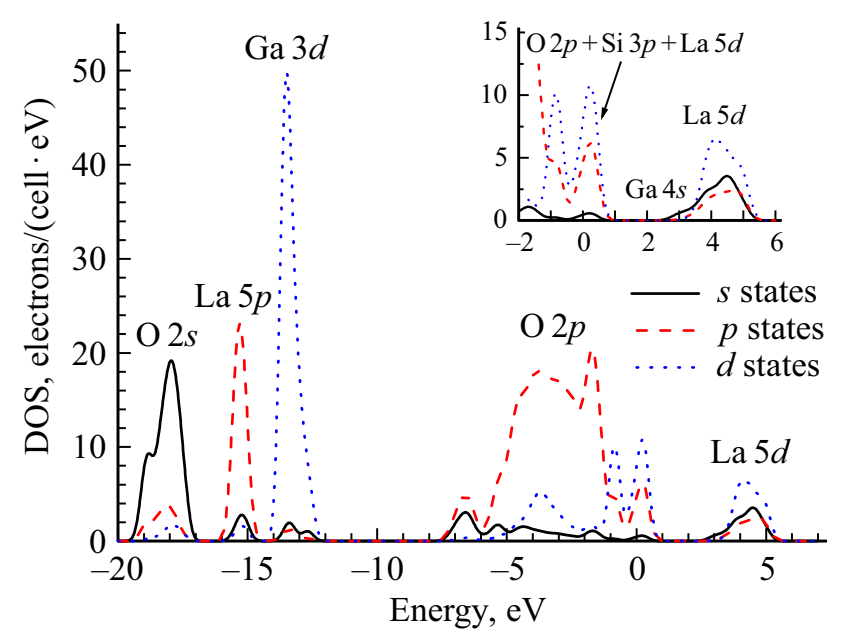

Рис. 2. Парциальные плотности электронных состояний, вносящих наибольший вклад в формирование энергетических зон LGS. На вставке представлена область потолка В3 и ЗП в увеличенном масштабе.

\section{2. Оптические свойства $\mathrm{La}_{3} \mathrm{Ga}_{5} \mathrm{SiO}_{14}$}

Спектры поглощения $\alpha(\lambda)$ кристалла LGS $\left(\mathrm{Ar}+2 \% \mathrm{O}_{2}\right)$ были получены из измеренных спектров пропускания и представлены на рис. 3. Наличие нескольких кривых с разной интенсивностью поглощения связано с разной ориентацией образцов и, следовательно, анизотропией пропускания. Смещение максимумов обусловлено наличием в кристаллах лангасита явления дихроизма - различия поглощения волн с взаимно перпендикулярными поляризациями $[1,36]$. Дихроизм свидетельствует, что центры окраски в кристаллах не изотропны.

Кристалл прозрачен в видимой и ближней УФ-области, с порогом при $250 \mathrm{~nm}$. В области прозрачности наблюдается четыре полосы поглощения при 280,340 , 370 и $480 \mathrm{~nm}$, а также полоса в ИК-области при $1850 \mathrm{~nm}$. Положение порога прозрачности при $250 \mathrm{~nm}$ согласуется с результатами, представленными ранее в работе [24], но заметно смещено в длинноволновую область относительно данных работы [27] $-235 \mathrm{~nm}$. Сме- 


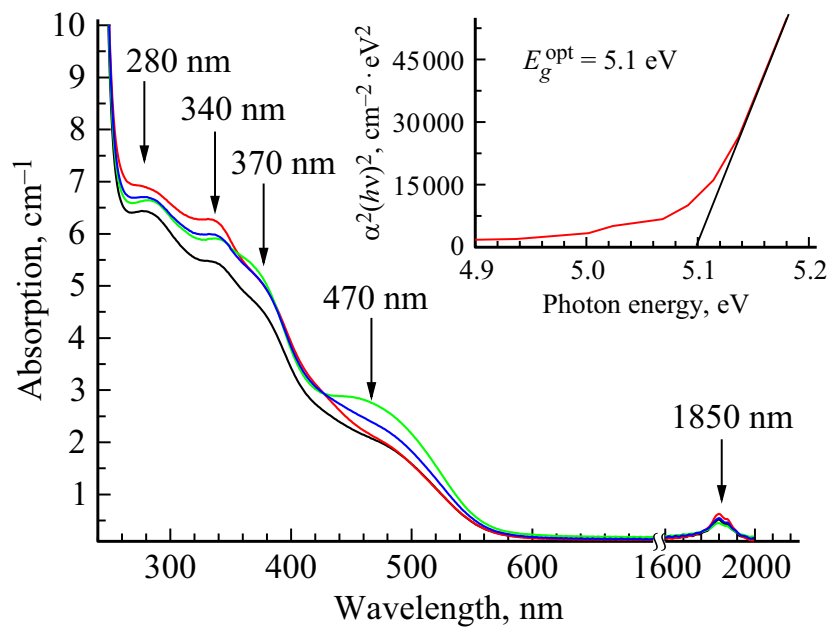

Рис. 3. Спектр поглощения кристалла LGS $\left(\mathrm{Ar}+2 \% \mathrm{O}_{2}\right)$, $T=300 \mathrm{~K}$. На вставке - рависимость $\alpha^{2}(h v)^{2}$ от энергии и экстраполяция линейного участка кривой к оси абсцисс.

щение порога может объяснятся разной температурой, при которой проводились измерения - $300 \mathrm{~K}$ в нашей работе и $8 \mathrm{~K}$ - в работе [27]. Уменьшение температуры обычно приводит к смещению порога поглощения в коротковолновую область из-за уменьшения величины электрон-фононного взаимодействия.

Была проведена оценка значения оптической ширины запрещенной зоны. На вставке рис. 3 представлена зависимость $(\alpha h v)^{n}$ от $h v$ (так называемое построение Таука), где $\alpha-$ коэффициент поглощения. Значение показателя степени $n$ зависит от характера межзонных переходов. В случае кристалла LGS значение $n=2$, что соответствует прямым разрешенным межзонным переходам, как это показано выше. Экстраполяция линейной части зависимости $(\alpha h v)^{n}$ к оси абсцисс позволяет оценить значение оптической ширины запрещенной зоны

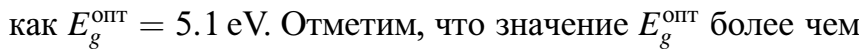
на $2 \mathrm{eV}$ превышает значение ширины запрещенной зоны, полученное при теоретическом расчете. Недооценка ширины запрещенной зоны в расчетах хорошо известна [37] и связана с принципиальной невозможностью точно учесть все корреляционные эффекты в рамках теории функционала плотности.

\section{3. Люминесцентные свойства $\mathrm{La}_{3} \mathrm{Ga}_{5} \mathrm{SiO}_{14}$}

Спектры люминесценции, измеренные с использованием синхротронного излучения энергии $E_{\text {возб }}=8 \mathrm{eV}$, представлены на рис. 4. Для кристалла LGS $E_{\text {возб }}>E_{g}$ и соответствует межзонным электронным переходам. При этом может возбуждаться как собственная люминесценция, так и люминесценция, связанная со структурными дефектами кристалла. В спектре люминесценции кристалла LGS (Ar) наблюдается одна широкая полоса с максимумом при $430 \mathrm{~nm}$. Спектр люминесценции LGS
$\left(\mathrm{Ar}+2 \% \mathrm{O}_{2}\right)$ заметно отличается от LGS (Ar). Широкая полоса люминесценции смещена в длинноволновую область и имеет максимум при $530 \mathrm{~nm}$. Отметим также, что спектр люминесценции LGS $\left(\mathrm{Ar}+2 \% \mathrm{O}_{2}\right)$ не является элементарным, так как на коротковолновом спаде основной полосы наблюдается плечо при $460 \mathrm{~nm}$. Таким образом, атмосфера роста влияет на люминесцентные свойства кристаллов LGS.

Спектры фотолюминесценции при селективном возбуждении представлены на рис. 5 и 6. В зависимости от длины волны возбуждения для кристалла LGS (Ar) наблюдались две полосы свечения с максимумами при 430 и $470 \mathrm{~nm}$. В спектрах возбуждения люминесценции наблюдается две полосы при 210 и $250 \mathrm{~nm}$. Отметим, что полосы люминесценции широкие и спектрально перекрываются, вследствие чего особенности спектров

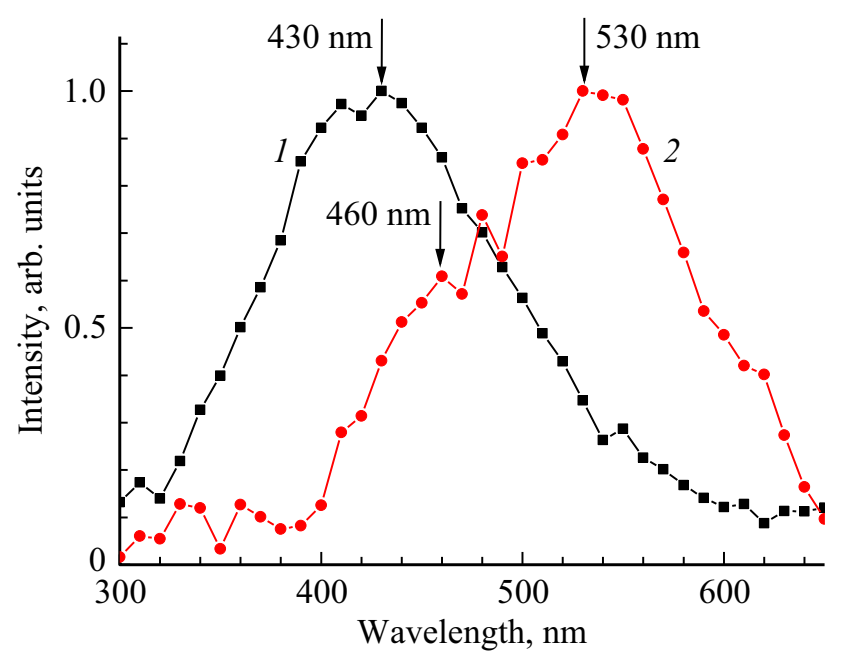

Рис. 4. Люминесценция кристаллов LGS (Ar) (1) и LGS $\left(\mathrm{Ar}+2 \% \mathrm{O}_{2}\right)(2), E_{\text {возб }}=8 \mathrm{eV}, T=15 \mathrm{~K}$.

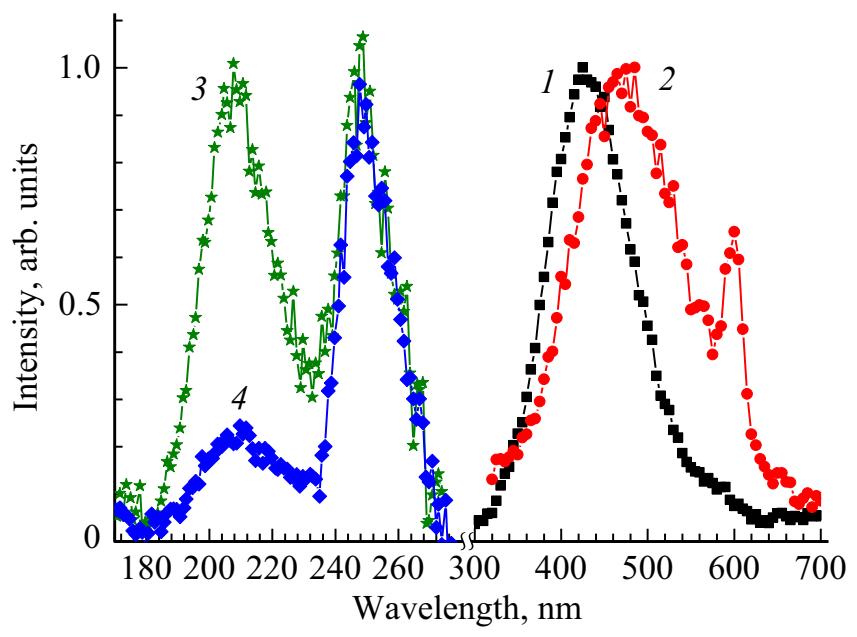

Рис. 5. Спектры люминесценции кристалла LGS(Ar) при $\lambda_{\text {возб }}=210 \mathrm{~nm}(1)$ и $250 \mathrm{~nm}(2)$, и спектры возбуждения при $\lambda_{\text {свеч }}=430 \mathrm{~nm}$ (3) и $510 \mathrm{~nm}(4), T=6 \mathrm{~K}$. Пик при $600 \mathrm{~nm}$ (кривая 2) связан с рассеянным светом в канале регистрации. 


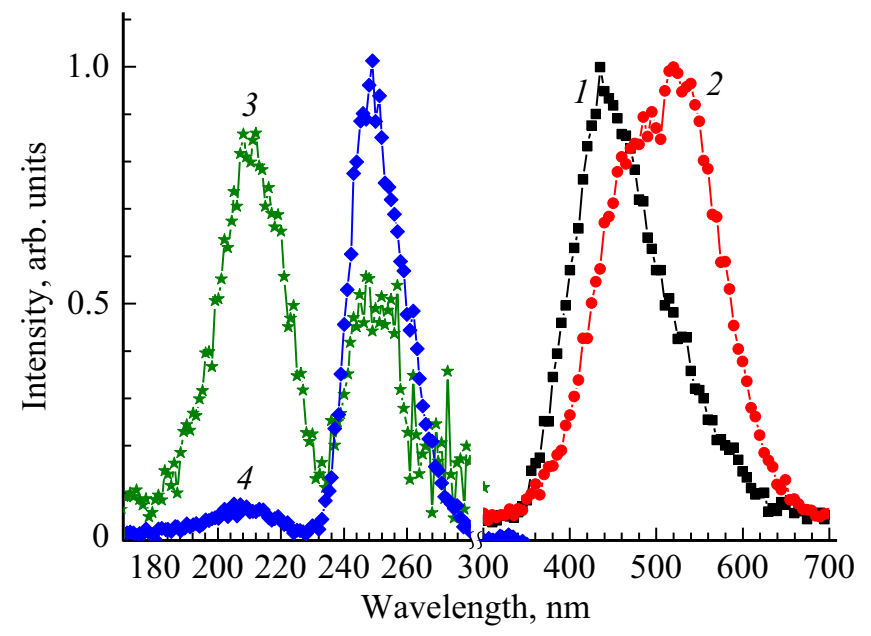

Рис. 6. Спектры люминесценции кристалла LGS $\left(\mathrm{Ar}+2 \% \mathrm{O}_{2}\right)$ при $\lambda_{\text {возб }}=210 \mathrm{~nm}(1)$ и $250 \mathrm{~nm}(2)$, и спектры возбуждения при $\lambda_{\text {свеч }}=400 \mathrm{~nm}(3)$ и $550 \mathrm{~nm}(4), T=6 \mathrm{~K}$.

возбуждения, характерные для одной полосы люминесценции, могут проявляться также в спектре возбуждения другой полосы.

Учитывая полученное выше значение $E_{g}^{\text {опт }}=5.1 \mathrm{eV}$ $(243 \mathrm{~nm})$, можно сделать вывод, что полоса возбуждения $210 \mathrm{~nm}$ соответствует области фундаментального поглощения кристалла, тогда как полоса $250 \mathrm{~nm}$ расположена до края области фундаментального поглощения, то есть в области прозрачности кристалла. Для кристалла LGS (Ar) полоса люминесценции с максимумом при $430 \mathrm{~nm}$ возбуждается в полосе $210 \mathrm{~nm}$, то есть в области фундаментального поглощения кристалла. Мы предполагаем, что данная полоса люминесценции имеет собственную природу и связана с излучательными переходами на регулярных комплексах кристалла. Природа собственных центров свечения, как правило, определяется природой электронных состояний, которые отвечают за формирование дна зоны проводимости и потолка валентной зоны. Согласно результатам расчета зонной структуры, дно зоны проводимости сформировано электронными состояниями галлия, тогда как потолок валентной зоны электронными состояниями кислорода. Таким образом, экситоны автолокализуются на $\mathrm{GaO}_{6}$ комплексах.

Полоса люминесценции при $470 \mathrm{~nm}$ наблюдается при возбуждении еще до края фундаментального поглощения с максимумом в спектре возбуждения при $250 \mathrm{~nm}$. Таким образом, данная полоса люминесценции возбуждается в области прозрачности кристалла и связывается с центрами свечения на комплексах, включающих в свой состав дефекты кристаллической структуры.

Спектры люминесценции кристалла LGS $\left(\mathrm{Ar}+2 \% \mathrm{O}_{2}\right)$ представлены на рис. 6. Собственная люминесценция автолокализованных экситонов наблюдается при возбуждении на полосе при $210 \mathrm{~nm}$. При возбуждении в области прозрачности кристалла $\lambda_{\text {возб }}=250 \mathrm{~nm}$ в спектре люминесценции наблюдается дополнительная полоса с максимумом при $530 \mathrm{~nm}$, тогда как полоса при $470 \mathrm{~nm}$ наблюдается в виде плеча. Спектр возбуждения для полосы $530 \mathrm{~nm}$ был измерен на длинноволновом спаде полосы для того, чтобы уменьшить вклад от спектров возбуждения других полос люминесценции. Однако, нами не наблюдалось новых особенностей в спектре возбуждения, что свидетельствует о том, что полосы люминесценции при 470 и $530 \mathrm{~nm}$ возбуждаются в полосе возбуждения при $250 \mathrm{~nm}$. Центры люминесценции обеих полос включают дефекты кристаллической структуры.

По данным, представленным в литературе [38] в кристаллах лангасита, выращенных в атмосфере $\mathrm{Ar}+(1 \%) \mathrm{O}_{2}$, могут наблюдаться различные типы точечных дефектов: вакансии кислорода $V_{\mathrm{O}}^{2+}$, вакансии лантана $V_{\mathrm{La}}^{3-}$ и галлия $V_{\mathrm{Ga}}^{3-}$, антиструктурные дефекты $\mathrm{Si}_{\mathrm{Ga}}^{+}$ и $\mathrm{Ga}_{\mathrm{Si}}^{-}$, а также комплексы $\left(V_{\mathrm{O}}^{2+}\right)^{x}-$ F-центры. Однако работ, посвященных влиянию атмосферы выращивания на точечные дефекты в LGS в литературе обнаружено не было.

Полоса люминесценции при $470 \mathrm{~nm}$ наблюдается как в кристалле LGS (Ar), так и в LGS $\left(\mathrm{Ar}+2 \% \mathrm{O}_{2}\right)$, тогда как полоса при $530 \mathrm{~nm}$ - только в кристалле LGS $\left(\mathrm{Ar}+2 \% \mathrm{O}_{2}\right)$. Таким образом, атмосфера роста не является определяющим фактором для проявления дефектов, которые формирует данный центр свечения. Структура точечных дефектов, а также люминесцентные свойства в зависимости от атмосферы выращивания были изучены для кристаллов изоморфных лангаситу - лантан-галлиевого танталата $\left(\mathrm{La}_{3} \mathrm{Ga}_{5.5} \mathrm{Ta}_{0.5} \mathrm{O}_{14}\right.$, LGT, лангатат) [39-41]. В частности, люминесцентным методом и методом ЭПР было показано, что антиструктурные дефекты $\mathrm{Ta}_{\mathrm{Ga}(2)}$, возникающие в LGT в результате высокой температуры синтеза, являются центрами свечения. Наличие этих центров не зависит от атмосферы роста. Мы полагаем, что антиструктурные дефекты $\mathrm{Si}_{\mathrm{Ga}}^{+}$или $\mathrm{Ga}_{\mathrm{Si}}^{-}$в LGS также могут служить центрами свечения и отвечают за возникновение полосы при $470 \mathrm{~nm}$.

Наличие полосы люминесценции при $530 \mathrm{~nm}$ зависит от атмосферы роста, а именно от наличия в ней кислорода. Аналогичная зависимость ранее наблюдалась нами для кристаллов LGT [40,41], где полоса свечения при $550 \mathrm{~nm}$ появляется у кристаллов, выращенных в атмосфере с кислородом. Был сделан вывод, что данная полоса связана с кислорододефицитными комплексами, возникающими из-за необходимости зарядовой компенсации неэквивалентного заселения октаэдрических узлов ионами $\mathrm{Ga}^{3+}$ и $\mathrm{Ta}^{5+}$. Кроме того, на основании комплексных исследований кристаллов LGT, выращенных в атмосфере $\mathrm{Ar}$ и $\mathrm{Ar}+(2 \%) \mathrm{O}_{2}$, в исходном состоянии и после ростовых отжигов, было показано, что основным типом дефектов в кристаллах, выращенных с добавлением кислорода являются F-центры $\left(V_{\mathrm{O}}^{2+}, 2 e^{-}\right)$[39]. Вероятнее всего, аналогичные типы дефектов должны наблюдаться и в кристаллах LGS $\left(\mathrm{Ar}+2 \% \mathrm{O}_{2}\right)$ и формировать центры свечения. 


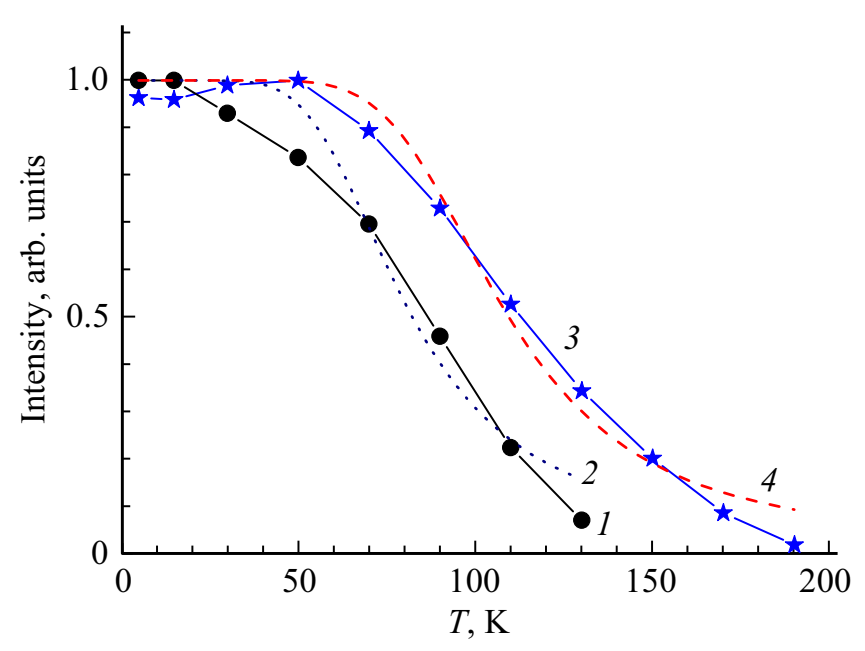

Рис. 7. Температурные зависимости интенсивности люминесценции LGS $\left(\mathrm{Ar}+2 \% \mathrm{O}_{2}\right): \lambda_{\text {свеч }}=380 \mathrm{~nm}$ при $\lambda_{\text {возб }}=210 \mathrm{~nm}$ (кривая 1); $\lambda_{\text {свеч }}=550 \mathrm{~nm}$ при $\lambda_{\text {возб }}=250 \mathrm{~nm}$ (кривая 3). Кривые (2) и (4) -- аппроксимация с использованием формулы Мотта кривых (1) и (3) соответственно.

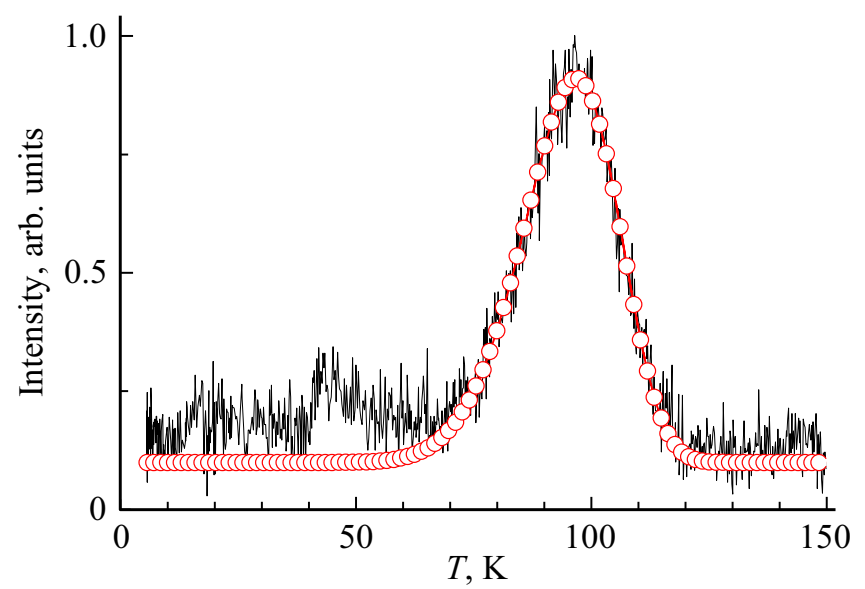

Рис. 8. Кривая ТСЛ (линия) и ее аппроксимация (полые точки) в приближении модели кинетики первого порядка для кристалла LGS $\left(\mathrm{Ar}+2 \% \mathrm{O}_{2}\right)$.

Были получены температурные зависимости интенсивности люминесценции LGS $\left(\mathrm{Ar}+2 \% \mathrm{O}_{2}\right)$ для полосы собственного свечения $430 \mathrm{~nm}$ и полосы свечения при $530 \mathrm{~nm}$ (рис. 7). Зависимости были измерены на коротковолновом спаде полосы $430 \mathrm{~nm}$ и на длинноволновом спаде полосы $530 \mathrm{~nm}$, чтобы уменьшить возможный вклад от широкой полосы свечения $470 \mathrm{~nm}$, которая спектрально перекрывается с этими полосами люминесценции. Видно, что интенсивность люминесценции уменьшается с увеличением температуры, что связано с процессом внутрицентрового тушения люминесценции. Интенсивность собственной люминесценции уменьшается на порядок величины при $T=120 \mathrm{~K}$, тогда как полоса при $530 \mathrm{~nm}$ показывает большую температурную стабильность и теряет в интенсивности порядок вели- чины при $T=170 \mathrm{~K}$. Для определения энергии активации температурного тушения, температурные зависимости интенсивности люминесценции кристаллов LGS $\left(\mathrm{Ar}+2 \% \mathrm{O}_{2}\right)$ были аппроксимированы с использованием формулы Мотта [42]

$$
I=\frac{1}{1+A \exp \left(\frac{E_{0}}{k T}\right)},
$$

где $T$ - температура, $A-$ коэффициент, представляющий произведение времени высвечивания люминесценции и дебаевской частоты $\left(\sim 10^{13} \mathrm{~s}^{-1}\right), E_{0}-$ энергия активации процесса, $k$ - постоянная Больцмана. Были получены следующие энергии активации процесса тушения $E_{0}=33 \mathrm{meV}$ для полосы $430 \mathrm{~nm}$ и $50 \mathrm{meV}$ для полосы $530 \mathrm{~nm}$ (рис. 7, кривые 2 и 4). Отметим, что температурная зависимость для собственной полосы люминесценции в LGS (Ar) аналогична представленной на рис. 7 , кривая 1 .

Измерения термостимулированной люминесценции позволяют получить информацию о наличии ловушек в кристалле. Как правило, такие ловушки связаны с дефектами кристаллической структуры, поэтому для измерений был выбран кристалл, LGS $\left(\mathrm{Ar}+2 \% \mathrm{O}_{2}\right)$, обладающий центрами окраски. Кривая термостимулированной люминесценции представлена на рис. 8 . На полученной зависимости наблюдается выраженный пик ТСЛ при $95 \mathrm{~K}$, а также слабый пик при $45 \mathrm{~K}$. Пик ТСЛ при $95 \mathrm{~K}$ был аппроксимирован в приближении модели кинетики первого порядка процесса (подробнее cм. $[43,44])$ для значений энергии активации ловушки $70 \mathrm{meV}$ и частотного фактора $150 \mathrm{~s}^{-1}$. Относительно малое значение величины частотного фактора связано с большим значением ширины пика ТСЛ. Вероятно, наблюдаемый пик ТСЛ представляет собой суперпозицию целого ряда элементарных пиков с близкими значениями энергии активации, которые варьируются из-за частичной разупорядоченности структуры кристалла LGS. Такое поведение характерно, например, для смешанных кристаллов, которые также характеризуются частичной разупорядоченностью структуры $[45,46]$.

Как было упомянуто во введении, ранее проводились единичные исследования люминесцентных свойств LGS, однако, результаты, представленные в работах [24,27-29], сильно отличаются (см. таблицу). Причина наблюдаемых отличий может быть объяснена с использованием результатов, полученных в настоящей работе. В работах $[24,28,29]$ результаты были получены при комнатной температуре. Как показано в настоящей работе, люминесценция LGS испытывает сильное температурное тушение при $300 \mathrm{~K}$. Кроме того, в случае энергий возбуждения, соответствующих области прозрачности кристалла $[28,29]$, возбуждаются только центры люминесценции, относящиеся к дефектам. Таким образом, авторы наблюдали ряд полос, связанных с центрами, включающими дефекты структуры, которые, 
по-видимому, определялись условиями роста исследованных кристаллов. Результаты, полученные в условиях низких температур как при межзонном, так и при внутризонном возбуждении были ранее представлены в [27] и хорошо согласуются с результатами, полученными в настоящей работе для кристалла LGS (Ar).

\section{4. Заключение}

Исследованы оптические и люминесцентные свойства нелегированных кристаллов лантан-галлиевого силиката. Проведенные расчеты структуры энергетических зон показали, что $\mathrm{La}_{3} \mathrm{Ga}_{5} \mathrm{SiO}_{14}$ является диэлектриком с запрещенной зоной, определяемой прямыми переходами в Г-точке зоны Бриллюэна. Определено значение ширины оптической запрещенной зоны кристалла $E_{g}^{\text {опт }}=5.1 \mathrm{eV}$. Проведены исследования влияния атмосферы роста на люминесцентные свойства $\mathrm{La}_{3} \mathrm{Ga}_{5} \mathrm{SiO}_{14}$. Показано, что для кристаллов, выращенных в атмосфере аргона, в спектре люминесценции доминирует полоса люминесценции с максимумами при $430 \mathrm{~nm}$, связанная с собственным свечением экситонов, автолокализованных на $\mathrm{GaO}_{6}$ комплексах. Для кристаллов, выращенных в атмосфере аргона с добавлением кислорода доминируют полосы люминесценции при 470 и $530 \mathrm{~nm}$, связанные с дефектами кристаллической структуры, а именно с антиструктурными дефектами дефекты $\mathrm{Si}_{\mathrm{Ga}}^{+}$или $\mathrm{Ga}_{\mathrm{Si}}^{-}$, а также кислорододефицитными комплексами. Показано влияние температуры на люминесцентные свойства, определены энергии активации процесса внутрицентрового температурного тушения на полосы люминесценции при 430 и $530 \mathrm{~nm}-33$ и $50 \mathrm{meV}$ соответственно. С использованием метода термостимулированной люминесценции показано наличие ловушек в лангасите, энергия активации обнаруженных ловушек определена как $70 \mathrm{meV}$.

\section{Список литературы}

[1] А.А. Каминский, Л.К. Аминов, В.Л. Ермолаев, А.А. Кониенко, В.Б. Кравченко, Б.З. Малкин, Б.В. Милль, Ю.Е. Перлин, А.Г. Петросян, К.К. Пухов, В.П. Сакун, С.Э. Саркисов, Е.Б. Свешникова, Г.А. Скрипко, Н.В. Старостин, А.П. Шкадаревич. Физика и спектроскопия лазерных кристаллов. Наука, М. (1986). 272 с.

[2] A.A. Kaminskii, B.V. Mill, G.G. Khodzhabagyan, A.F. Konstantinova, A.I. Okorochkov, I.M. Silverstrova. Phys. Status Solidi A 80, 387 (1983).

[3] A.A. Kaminskii. Phys. Status Solidi A 87, 11 (1985).

[4] Б.В. Гринев, М.Ф. Дубовик, А.В. Толмачев. Оптические монокристаллы сложных оксидных соединений. Институт монокристаллов, Харьков (2002). 252 с.

[5] И.А. Андреев, М.Ф. Дубовик. Письма в ЖТФ 10, 487 (1984).

[6] H. Fritze, O. Schneider, H. Seh, H.L. Tuller, G. Borchardt. Phys. Chem. 5, 5207 (2003).

[7] H. Ohsato, T. Iwataki, H. Morikoshi, K. Kakimoto. Ceram. Int. 39, S87 (2013).

[8] S. Uda, O. Buzanov. J. Cryst. Growth. 211, 318 (2001).
[9] S. Uda, S.Q. Wang, N. Konishi, H. Inaba, J. Harada. J. Cryst. Growth. 237-239, 707 (2002).

[10] Z. Wang, Y. Yin, D. Yuan. J. Alloys Comp. 436, 364 (2007).

[11] Z. Wang, D. Yuan, X. Shi, X. Cheng, D. Xu, M. Lv, L. Pan, S. Guo. J. Cryst. Growth 257, 141 (2003).

[12] Q. Wang, L. Su, H. Li, L. Zheng, X. Xu, H. Tang, D. Jiang, F. Wu, J. Xu. Chin. Phys. B 21, 026101 (2012).

[13] Z. Wang, D. Yuan, X. Shi, X. Cheng, D. Xu, M. Lu, L. Pan. J. Cryst. Growth. 263, 246 (2004).

[14] S. Georgescu, O. Toma, A.M. Chinie, L. Gheorghe, A. Achim, A.S. Stefan. Opt. Mater. 30, 1007 (2008).

[15] Q. Wang, Zh. Wei, J. Liu, Zh. Wang, Zh. Zhang, H. Zhang, J. Wang. Conf. on Lasers and Electro-Optics Pacific Rim. ThA3-7 (2013).

[16] А.А. Каминский. ДАН СССР. Сер. физ. 33, 849 (1988).

[17] X.H. Fu, Y. Che, Y.L. Li. Solid State Liquid Lasers 21, 995 (2011).

[18] А.А. Каминский, Г.Р. Вердун, Б.В. Милль, А.В. Буташин. Неорган. материалы 27, 141 (1992).

[19] Л.Н. Алябьева, В.И. Бурков, В.А. Котов. Радиоэлектроника и электроника 62, 175 (2017).

[20] В.И. Бурков, Л.Н. Алябьева, Ю.В. Денисова, Б.В. Милль. Неорган. материалы 50, 1210 (2014).

[21] В.И. Бурков, С.В. Гуденко, Л.Н. Алябьева. ЖЭТФ 146, 820 (2014).

[22] P.G. Zverev, G.V. Shilova. Book of abstracts. Laser Physics Workshop 2015. Seminar 5 (2015).

[23] J.-X. Lui, Z.-H. Wang, W.-L. Tian, Q. Wang, Z.-G. Zhang, Z.-Y. Wei, H.-H. Yu, H.-J. Zhang, J.-Y. Wang. Chin. Phys. Lett. 32, 014206 (2015).

[24] Y. Futami, T. Yanagida, Yu. Fujimoto, V. Jary, J. Pejchal, Yu. Yokota, M. Kikuchi, M. Nikl, A. Yoshikawa. Opt. Mater. 34, 1513 (2012).

[25] O.A. Buzanov, A.V. Naumov, V.V. Nechaev, S.N. Knyazev. Proc. 1996 IEEE Int. Freq. Control Symp. 131 (1996).

[26] Н.С. Козлова, О.А. Бузанов, Е.В. Забелина, А.П. Козлова, М.Б. Быкова. Кристаллография 61, 275 (2016).

[27] M. Itoh, S. Takagi, M. Kitaura, M. Fujita, N. Endo. J. Lumin. 122-123, 205 (2007).

[28] W. Zhang, J. Wang, Zh. Ji, H. Li, Y. Lou, S. Yao. J. Rare Earths. 28, 420 (2010).

[29] Y. Hu, F. Wang, H. Lin. Mater. Chem. Phys. 107, 82 (2008).

[30] T. Balasubramanian, B.N. Jensen, S. Urpelainen, B. Sommarin, U. Johansson, M. Huttula, R. Sankari, E. Nõmmiste, S. Aksela, H. Aksela, R. Nyholm. AIP Conf. Proc. 1234, 661 (2010).

[31] S.J. Clark, M.D. Segall, C.J. Pickard, P.J. Hasnip, M.J. Probert, K. Refson, M.C. Payne. Z. Kristallogr. 220, 567 (2005).

[32] J.P. Perdew, K. Burke, M. Ernzerhof. Phys. Rev. Lett. 77, 3865 (1996).

[33] D.M. Ceperley, B.J. Alder. Phys. Rev. Lett. 45, 45 (1980).

[34] J.P. Perdew, A. Zunger. Phys. Rev. B 23, 5048 (1981).

[35] M. Kitaura, K. Mochizuki, Y. Inabe, M. Itoh, H. Nakagawa, S. Oishi. Phys. Rev. B 69, 115120 (2004).

[36] А.А. Майер. Физическая химия твердого тела. Кристаллооптика. Изд-во МХТИ им. Менделеева, М. (1984). 84 с.

[37] R.O. Jones, O. Gunnarsson. Rev. Mod. Phys. 61, 689 (1989).

[38] G.M. Kuz'micheva, I.A. Kaurova, V.B. Rybakov, S.S. Khasanov, A. Cousson, O. Zaharko, E.N. Domoroshchina, A.B. Dubovskii. Cryst. Res. Technol. 47, 131 (2012). 
[39] Е.В. Забелина Неоднородности в кристаллах лантан-галлиевого танталата и их влияние на оптические свойства. Автореф. дис. М. (2017). 24 с.

[40] D.A. Spassky, M.G. Brik, N.S. Kozlova, A.P. Kozlova, E.V. Zabelina, O.A. Buzanov, A. Belsky. J. Lumin. 177, 152 (2016).

[41] D.A. Spassky, N.S. Kozlova, A.P. Kozlova, E.V. Zabelina, O.A. Buzanov, M. Buryi, V. Laguta, K. Lebbou, A. Nehari, H. Cabane, M. Dumortier, V. Nagirnyi. J. Lumin. 180, 95 (2016).

[42] R.W. Gurney, N.F. Mott. Trans. Faraday Soc. 35, 69 (1939).

[43] V.V. Mikhailin, A.N. Vasil'ev. Introduction to solid-state spectroscopy. MGU, M. (1987). $191 \mathrm{c}$.

[44] D.A. Spassky, V. Nagirnyi, V.V. Mikhailin, A.E. Savon, A.N. Belsky, V.V. Laguta, M. Buryi, E.N. Galashov, V.N. Shlegel, I.S. Voronina, B.I. Zadneprovski. Opt. Mater. 35, 2465 (2013).

[45] J. Ueda, P. Dorenbos, A.J.J. Bos, K. Kuroishi, S. Tanabe. J. Mater. Chem. C 3, 5642 (2015).

[46] O. Voloshyna, O. Sidletskiy, D. Spassky, Ia. Gerasymov, A. Belsky. Opt. Mater. 76, 382 (2018).

Редактор Т.Н. Василевская 